\title{
A identificação humana de vítimas de desastres em massa: a importância e o papel da Odontologia Legal
}

\section{Human identification of victims of mass disasters: the importance and role of Forensic Dentistry}

\author{
Laís Gomes de Araujo \\ Roberto César Biancalana** \\ Andrea Sayuri Silveira Dias Terada** \\ Luiz Renato Paranhos ${ }^{* * * *}$ \\ Carlos Eduardo Palhares Machado ${ }^{* * * *+}$ \\ Ricardo Henrique Alves da Silva ${ }^{* *+* *+*}$
}

\section{Resumo}

A identificação humana é uma das principais atividades desenvolvidas pela Odontologia Legal. Os desastres em massa são os acidentes, naturais ou produzidos diretamente pela ação ou pela influência humana, que geralmente resultam em um elevado número de vítimas fatais. Os corpos, muitas vezes, encontram-se carbonizados, fragmentados, destruídos ou em processo de decomposição avançada, o que dificulta a identificação das vítimas. Os métodos odontológicos são comumente usados nesses casos, pois os dentes possuem alta resistência e, muitas vezes, são a única fonte que determina a identidade de um indivíduo. Objetivo: analisar, por meio da revisão de diferentes casos da literatura, a importância da Odontologia Legal no processo de identificação humana nos desastres em massa e o trabalho do perito odontolegista. Materiais e método: realizou-se um levantamento bibliográfico, com base em artigos científicos que relatam casos reais em que o método odontológico de identificação humana foi executado e

sua aplicabilidade foi analisada, verificando suas vantagens, limitações e eficiência. Resultados: constatou-se que a Odontologia apresenta uma relevante contribuição para a identificação das vítimas em eventos com múltiplas fatalidades. Não raro, o método odontológico de identificação humana apresentou-se como o único passível de emprego em casos com número demasiado de vítimas fatais ou em situações em que os corpos apresentavam-se com a integridade comprometida. Considerações finais: a Odontologia Legal desempenha um importante papel no processo de identificação de vítimas de desastres em massa, pelo fato de os dentes possuírem características que possibilitam o processo de identificação de um indivíduo, sendo, em algumas situações, o único material passível de análise.

Palavras-chave: Desastres em massa. Identificação humana. Odontologia Legal.

Cirurgiã-dentista, mestranda em Biologia Oral e aluna do curso de especialização em Odontologia Legal, Faculdade de Odontologia de Ribeirão Preto (USP), São Paulo, Brasil.

Cirurgião-dentista, especialista em Odontologia Legal e mestrando em Biologia Oral, Faculdade de Odontologia de Ribeirão Preto (USP), São Paulo, Brasil.

**** Cirurgiã-dentista, mestra em Biologia Oral e especialista em Odontologia Legal, Faculdade de Odontologia de Ribeirão Preto (USP), São Paulo, Brasil.

**** Cirurgião-dentista, professor adjunto no Departamento de Odontologia, Universidade Federal de Sergipe, Lagarto, Sergipe, Brasil. Cirurgião-dentista, perito criminal federal - área Odontologia, Instituto Nacional de Criminalística, Departamento de Polícia Federal, Brasilia, Brasil.

${ }^{* * * * * *}$ Cirurgião-dentista, professor doutor na área de Odontologia Legal, Faculdade de Odontologia de Ribeirão Preto (USP), São Paulo, Brasil. 


\section{Introdução}

A Odontologia Legal é uma das áreas das Ciências Forenses responsável pela investigação de fenômenos psíquicos, físicos, químicos e biológicos que podem atingir os seres humanos (vivo, morto, ossada e fragmentos) ${ }^{1}$. Dentre suas competências, destaca-se a identificação humana, na qual a Odontologia Legal pode oferecer um grande poder de colaboração junto à Medicina Legal e ao Direito na busca pela identidade de um indivíduo ${ }^{2-4}$.

A identidade é o conjunto de características morfofisiológicas e psíquicas exclusivas de uma pessoa, sendo definida por processo objetivo, baseado em fundamentos científicos ${ }^{2,3}$. É um dever do Estado e direito de todo cidadão ser identificado ${ }^{5}$. Com isso, os princípios éticos e morais que norteiam a sociedade levam a que todos os esforços disponíveis sejam utilizados para localizar e identificar o maior número possível de pessoas envolvidas em uma tragédia ${ }^{4,5}$.

Os desastres em massa são acidentes súbitos, naturais ou produzidos diretamente pela ação ou influência do homem, que resultam no sofrimento ou na perda da vida humana e que ultrapassam a capacidade assistencial, técnica e socorrista local, onde os recursos estão indisponíveis ou esgotados ${ }^{6,7}$. Em alguns desses eventos, os corpos das vítimas sofrem ações destruidoras e degenerativas por meio de agentes físicos, químicos, mecânicos ou biológicos, resultando, muitas vezes, em corpos carbonizados, fragmentados, macerados, mutilados ou em avançado estado de decomposição, o que dificulta ou impossibilita o reconhecimento pela inspeção visual e a identificação pelo método datiloscópico, uma vez que as polpas digitais são destruídas no processo de degeneração do $\operatorname{corpo}^{8-10}$.

Uma das maiores virtudes do método de identificação pela análise dos arcos dentais é a sua eficiência em situações adversas, pois os dentes são estruturas altamente mineralizadas, que possuem grande durabilidade, longevidade e alta resistência a condições extremas de degradação, como alterações de pressão, temperatura e umidade ${ }^{5,7,8}$. O método odontológico também apresenta menor tempo de trabalho quando comparado ao exame de DNA, além de excelente confiabilidade, desde que realizado com critério e minúcia, sendo, em determinadas condições, o único passível de aplicação $0^{9,11}$.

Considerando o valioso papel da Odontologia Legal no processo de identificação de vítimas em grandes acidentes ${ }^{2,5,9}$, o objetivo deste trabalho foi analisar, por meio de diferentes casos publicados na literatura, a importância da Odontologia Legal no processo de identificação humana nos desastres em massa.

\section{Revisão de literatura}

Valenzuela et al. ${ }^{9}$ relataram a identificação de 28 vítimas carbonizadas em um acidente de ônibus em fevereiro de 1996, no sul da Espanha. A identidade dos corpos foi estabelecida em 57\% dos casos por meio dos dentes. Em 18\% das vítimas, a identificação foi pelo método dental associado a outras técnicas forenses. No entanto, em $43 \%$ das vítimas, a comparação dental não pôde ser realizada, devido à completa destruição dos dentes ou à ausência de registros ante-mortem.

Dumancic et al. ${ }^{12}$ relataram a importância da utilização dos métodos odontológicos na identificação de vítimas em dois acidentes: primeiramente, em acidente ferroviário em 1974, com 152 vítimas fatais, 111 delas foram identificadas, e apenas $5 \%$ desses casos utilizaram a identificação dental; e, posteriormente, em 1976, numa colisão envolvendo uma aeronave britânica - em que todos os 63 passageiros foram identificados, tendo, em $33 \%$ dos casos, as características dentais sido cruciais - e uma aeronave eslovena - em que, dos 103 mortos identificados, $14 \%$ da identificação foi obtida, exclusivamente, pelos dentes. Os autores destacaram que a razão para os diferentes números de identificações dentais nas vítimas de ambos os acidentes é explicada pela disposição e precisão dos dados odontológicos fornecidos por parentes e amigos das vítimas.

Em 2002, Valenzuela et al. ${ }^{13}$ analisaram as vantagens e as limitações dos métodos de identificação dental nos corpos carbonizados em dois acidentes de ônibus na Espanha. No primeiro acidente, em 1996, dos 28 corpos, 16 foram identificados pelo método dental, enquanto no segundo acidente, em 1997, dos 10 corpos, 8 foram identificados a partir dos arcos dentais. Nessa comparação, os autores concluíram que o sucesso na identificação odontológica está relacionado à natureza do acidente, à nacionalidade das vítimas, à incidência dos tratamentos odontológicos, à disponibilidade de registros dentais adequados ante-mortem e ao estado dental post-mortem.

Brannon e Morlang ${ }^{14}$ relataram o importante papel da Odontologia Legal na identificação humana das vítimas de suicídios e assassinatos provocados por cianeto e armas de fogo envolvendo uma seita religiosa em novembro de 1978, na Guiana, que resultou em 913 mortos. Dessas vítimas, os meios odontológicos foram utilizados para identificar um total de 223 (33\%) corpos. A comparação dental ante e post-mortem foi o único método utilizado para 73 (11\%) dessas vítimas, ao passo que em $150(22 \%)$ pessoas foram feitos os exames dos arcos dentais juntamente com o da impressão digital. Os principais problemas encontrados pela equipe odontológica na identificação das vítimas desse desastre foram a perda das estruturas dentais post-mortem e os dados odontológicos inadequados, prejudicando o 
exame odontológico. Outro problema que limitou a identificação dos corpos pela equipe odontológica foi a falta de dados relacionados às próteses dentais, uma vez que muitos adultos e idosos mortos nessa tragédia eram usuários de aparelhos protéticos. A identificação de crianças também foi dificultada, pois muitas delas não possuíam exames dentais ante-mortem ou, quando os possuíam, eram apenas dos dentes decíduos.

Compobasso, Flamingo e Vinci ${ }^{15}$ relataram o desmoronamento de um prédio na Itália, em 1999, no qual a maior parte das vítimas estava preservada, sendo reconhecidas visualmente por meio de características individuais externas (cicatrizes, tatuagens, marcas no corpo), das vestimentas e dos objetos pessoais. Apenas dois corpos carbonizados foram identificados a partir da comparação dos registros dentais ante e post-mortem e confirmados, posteriormente, pela análise de DNA.

No mesmo ano, Poisson et al. ${ }^{16}$ investigaram quatro diferentes desastres na França, com o intuito de revelar a eficiência da Odontologia na identificação de corpos carbonizados, desfigurados e em decomposição. Do total de 55 vítimas fatais envolvidas nos acidentes descritos, 38 foram identificadas a partir da análise dental comparativa ante e post-mortem, em um curto período de tempo (24 a 48 horas), o que correspondeu a uma taxa de sucesso de $69 \%$ e na diminuição dos atrasos na identificação.

Brannon e Morlan ${ }^{3}$ (2004) descreveram a contribuição da Odontologia na identificação humana em um acidente militar da marinha americana em 1989, em Porto Rico, quando uma explosão vitimou 47 tripulantes. A identificação dental foi o principal método utilizado na identificação da maioria das vítimas, uma vez que os restos mortais estavam gravemente queimados, fragmentados ou em estado avançado de decomposição. Para utilização da técnica forense odontológica, foi necessário obter os exames radiográfico e dental das vítimas, recorrendo às fichas clínicas e radiografias ante-mortem dos indivíduos, para comparação. Em 14 vítimas, o método dental empregado foi suficiente para identificação. Em 31 pessoas, houve a combinação da impressão digital e comparação dental. Além disso, em dois indivíduos, os achados dentais foram classificados como "consistentes" e, posteriormente, confirmados por meio da datiloscopia.

Em 2006, Valck ${ }^{17}$ determinou a importância da criação de métodos padrões de identificação em desastres em massa. O tsunami no continente asiático, em 2004, devastou a região costeira de mais de dez países em torno do Oceano Índico, causando a morte de mais de 200 mil pessoas. Desses indivíduos, mais de 58 nacionalidades estavam entre as vítimas. Um trabalho coletivo entre as equipes de desastres em massa de diferentes países foi realizado a partir da criação dos protocolos operacionais, do estabelecimento de um padrão para os procedi- mentos post-mortem de coleta de dados e exames de impressão digital, de Medicina Legal, de Odontologia Forense e de DNA. Os métodos dentais possibilitaram a identificação em cerca de $85 \%$ dos casos, concluindo-se que, para um efetivo resultado, as informações dentais ante-mortem devem ser coletadas e armazenadas logo após o desastre, no intuito de maximizar a eficácia do processo de identificação.

Naiman et al. ${ }^{18}$ evidenciaram os procedimentos legais e as técnicas forenses aplicadas frente a um ataque terrorista e observaram o papel fundamental dos profissionais da Odontologia Forense na identificação humana por meio dos arcos dentais, com a realização de radiografias, exame clínico dental e coleta de dados ante-mortem para realização do confronto com os dados post-mortem obtidos.

Para Nuzzolese e Vella ${ }^{19}$, as principais dificuldades na identificação de vítimas em um desastre em massa estão relacionadas a vários fatores, como: o estado em que os corpos são encontrados (ex: fragmentados, queimados); o estabelecimento de uma lista com as potenciais vítimas do acidente; a coleta de registros médicos e odontológicos das vítimas; as questões legais, jurídicas, organizacionais e políticas; a disponibilização de documentos internos e externos; as falhas de comunicação envolvendo todos os profissionais que trabalham efetivamente no desastre; além da não aplicação do código universal da identificação humana forense.

Hinchliffe $^{5}$ relatou a contribuição da Odontologia no acidente com o voo Comair 191 (Delta 5191), em 2006, que matou 49 dos 50 passageiros e tripulantes. Dos mortos, 47 foram identificados por métodos dentais, estando entre os fatores que resultaram no sucesso desta identificação: o conhecimento da lista das vítimas, a boa conservação da maioria dos corpos, o planejamento operacional eficaz, a boa comunicação entre as equipes envolvidas na tragédia, a presença de registros dentais ante-mortem da maioria das vítimas, o número de mortos relativamente pequeno e a boa infraestrutura nas instalações e nos equipamentos.

Ainda no mesmo ano, Sweet $^{20}$ realizou uma revisão de literatura sobre a atuação do odontolegista na identificação humana por meio de métodos odontológicos, destacando que os cirurgiões-dentistas forenses têm um papel fundamental nos desastres em massa, buscando estabelecer a identidade das vítimas a partir da comparação entre os registros odontológicos ante e post-mortem.

Melo et al. ${ }^{21}$, em 2010, baseados nos inúmeros desastres ocorridos nos últimos tempos - como o atentado terrorista às "Torres Gêmeas" nos EUA (2001), o tsunami na Ásia (2004) e os recentes acidentes aéreos no Brasil: Gol (2006), TAM (2007) e Air France (2009) -, ressaltaram a importância do cirurgião-dentista, tanto no âmbito clínico quanto na área do desastre, assim como das técnicas de 
identificação utilizadas em Odontologia Forense, área que vem se aprimorando, a cada dia, na busca de tecnologias que permitam resultados mais sensíveis, específicos, rápidos e eficazes. Segundo os autores ${ }^{22}$, a identificação do cadáver pelos arcos dentais oferece grande precisão, e é necessário que os dados registrados pelo cirurgião-dentista descrevam com detalhes a real situação da cavidade bucal dos seus pacientes.

Leite et al. ${ }^{22}$, em 2011, analisaram o perfil profissional e a atuação do odontolegista nas atividades de identificação de vítimas de desastres aéreos de grandes proporções ocorridos na última década, no Brasil (Gol Linhas Aérea, 2006; TAM Linhas Aérea, 2007; Air France, 2009), por meio de entrevista com cirurgiões-dentistas que participaram ativamente desses processos. De acordo com a literatura pesquisada e os dados obtidos com a entrevista, os autores puderam concluir que a atuação do odontolegista é de fundamental importância no processo de identificação de vítimas de acidentes aéreos, devendo esse profissional estar apto a atuar nesse tipo de situação. Além disso, verificaram que a comparação odontológica é imprescindível no processo de identificação de vítimas de acidentes de massa, podendo ser utilizada de forma isolada ou em conjunto com outras técnicas. Entretanto, existem dificuldades na busca pela identidade, como o severo grau de carbonização, fragmentação e destruição dos corpos e a ausência ou baixa qualidade de informações presentes no material ante-mortem utilizado para realização de confronto odontológico.

\section{Discussão}

É incontestável a atuação dos odontolegistas nos trabalhos de identificação de vítimas provenientes de grandes desastres coletivos. Além disso, esses profissionais são importantes no auxílio nos procedimentos de emergência das vítimas, na busca e no salvamento, na participação em equipes de primeiros socorros, no atendimento de emergência odontológica, nos cuidados dentais e na busca pelas informações capazes de auxiliar na elucidação das causas da morte ${ }^{2,11,19,23}$.

Diante do forte impacto emocional, da comoção social gerada e da extrema responsabilidade na busca incessante pela identificação dos corpos envolvidos em um desastre em massa, não é recomendável a realização das atividades periciais por profissionais sem a devida formação específica ou treinamento em Odontologia Legal ${ }^{2,5}$. As atividades desenvolvidas por esses profissionais podem trazer sérias implicações civis e/ou criminais, quando realizadas de forma errônea ou descuidada ${ }^{18}$.

As perícias envolvendo assuntos inerentes à Odontologia devem ser realizadas somente por pessoas habilitadas nessa área do conhecimento, ou seja, apenas por cirurgiões-dentistas, não sendo admitida a delegação do exame pericial odontológico aos profissionais com formação diversa ${ }^{22,24,25}$. É preferível que os profissionais sejam especialistas em Odontologia Legal, pela implicação dos conhecimentos técnicos e da experiência em protocolos de identificação humana ${ }^{22}$. Os odontolegistas são profissionais treinados e habilitados para realizar a análise, perícia e avaliação dos eventos relacionados a esse tipo de situação, pois são especialistas na área forense e, dessa forma, conhecedores de noções de Medicina Legal, Sociologia, Criminalística e Direito, que abrange leis e códigos universais, além dos já mencionados conhecimentos específicos da Odontologia, conhecimentos técnicos e experiências em protocolos de identificação humana ${ }^{3,10,11,19,24}$.

Os desastres em massa são eventos súbitos e inesperados, que, pelo alto número de vítimas ou pela condição de conservação dos corpos, ultrapassam a capacidade de demanda funcional e estrutural habitual da localidade ${ }^{4,12}$. Um desastre em massa nunca é igual ao outro, e cada caso exige diferentes respostas, que sempre devem ser imediatas, organizadas e coordenadas. As dificuldades operacionais em torno dessas catástrofes, geralmente, são semelhantes: grande número de restos mortais; restos fragmentados, dispersos e queimados; dificuldade para determinar a vítima envolvida no desastre; obtenção de registros médicos e odontológicos significativos; assuntos de índole legal, jurisdicional, organizacional e política; documentação interna e externa e problemas de comunicação ${ }^{11,23,24,26}$.

Nas situações em que não houver vítimas com vida, as equipes forenses devem voltar-se para os restos materiais, procedendo de forma íntegra, conjunta e multidisciplinar para, posteriormente, atuarem na identificação humana ${ }^{23,25,26}$. Diante desse cenário, possivelmente, o local estará repleto de vestígios, sendo alguns totalmente relacionados à área odontológica, como fragmentos do crânio, da maxila, da mandíbula e seus respectivos elementos dentais, peças anatômicas que podem ser decisivas para o ato da identificação e que somente o odontolegista estará plenamente capacitado para averiguar e manusear com o cuidado necessário, para que não haja fraturas ou perdas ${ }^{20,24}$.

A identificação odontológica, de acordo com o Guia de Disaster Victim Identification (DVI) da Interpol ${ }^{26}$, é considerada um método primário de identificação, assim como a datiloscopia e o exame de DNA, que atende de forma positiva aos requisitos técnicos e biológicos (unicidade, imutabilidade, perenidade, classificabilidade e praticabilidade) de um processo de identificação humana ${ }^{9,13,17}$.

Durante o processo de investigação da identidade das vítimas, são realizadas três etapas: a busca de informações ante-mortem, a coleta e o exame de evidências post-mortem e a comparação entre eles ${ }^{5,9,13,17}$. 
Por meio do contato com os familiares das vítimas, é possível a obtenção de informações odontológicas ante-mortem, como prontuários odontológicos, contendo ficha clínica, radiografias dentais, modelos em gesso, fotografias do sorriso, informações sobre próteses dentais, placas de clareamento e outros materiais que possam ser relevantes para análise pericial $^{5-7}$. Desse modo, verifica-se a importância do prontuário odontológico confeccionado pelo cirurgião-dentista, sendo, muitas vezes, decisivo nos casos de identificação humana, otimizando o tempo e o custo do trabalho pericial ${ }^{21}$. A documentação odontológica deve estar completa, bem assinalada e ter uma correta elaboração, guarda e manutenção em arquivos próprios para possíveis identificações em caso de catástrofe ${ }^{6,7,21}$.

No exame detalhado da boca, deve ser investigada a presença de fraturas dentais, restaurações, aparelhos e bandas ortodônticas, implantes, tratamentos endodônticos, próteses fixas e removíveis, bem como qualquer outra característica capaz de individualizar a vítima ${ }^{5,7,10,19,20,25}$. Recomenda-se que os odontolegistas utilizem a técnica de verificação múltipla ${ }^{7}$, na qual um cirurgião-dentista examina, outro registra e um terceiro refaz o exame feito pelo primeiro, e, após essa etapa, os profissionais devem alterar a ordem em que examinam cada vítima, no intuito de comparar e aumentar a confiabilidade dos resultados ${ }^{6,10,20,24}$.

De acordo com o Manual da American Board of Forensic Odontology $(\mathrm{ABFO})^{27}$, a identificação humana pode conduzir às seguintes conclusões: identificação positiva - quando os dados ante e post-mortem forem concordantes com detalhes suficientes e nenhuma discrepância inexplicável; identificação possível - quando existem características semelhantes, porém não se pode afirmar com convicção que são totalmente compatíveis; insuficiente quando a informação disponível é de má qualidade ou insuficiente para formar a base de uma conclusão; exclusão - quando os dados ante e post-mortem são claramente inconsistentes.

A taxa de sucesso na identificação pelos arcos dentais depende da natureza do acidente, que determinará as condições dos corpos encontrados e seus graus de mutilação, fragmentação e carbonização, e assim, consequentemente, o estado dos elementos dentais post-mortem; da obtenção e qualidade dos registros ante-mortem ${ }^{5,7,10}$; do tipo de população, que pode se tratar de um grupo fechado, ou seja, que envolva um número limitado de pessoas, onde há, possivelmente, informações prévias sobre a quantidade de vítimas, ou um grupo aberto em que não existem quaisquer informações precedentes, o que dificulta o processo de busca pela identidade dos corpos; da nacionalidade das vítimas, pois nos casos que abrangem pessoas de mais de uma nacionalidade, pode ser necessária a solicitação de apoio de outras equipes internacionais, referentes aos países envol- vidos, para realização de um trabalho em conjunto das equipes forenses nacionais e internacionais ${ }^{26}$.

A perda de estruturas dentais post-mortem e a falta de identificação das próteses dentais são fatores que dificultam e limitam as investigações da identidade dos corpos pela equipe de odontolegistas ${ }^{6}$. A identificação de crianças pode levar a maiores dificuldades na obtenção de resultados do ponto de vista odontológico, porque normalmente, apresentam pouco ou nenhum registro dental ante-mortem ou quando existente, referem-se à dentição decídua ${ }^{7,10,14}$.

\section{Considerações finais}

Observa-se que a Odontologia Legal desempenha um importante papel no processo de identificação de vítimas de desastres em massa, visto que em algumas situações o dente é o único material passível de análise.

\section{Abstract}

Human identification is one of the main activities developed by Forensic Dentistry. Mass disasters are accidents either natural or directly caused by human action or influence, which usually result in a high death toll. Bodies are often charred, fragmented, destroyed, or in advanced decomposition, which complicates the process of identifying the victims. Dental methods are commonly used in these cases due to the high resistance of the teeth. Hence, they are frequently the only source that may determine the identity of an individual. Objective: to analyze through the review of different cases in literature, the importance of Forensic Dentistry in the process of human identification in mass disasters, as well as the role of the forensic dentist. Materials and methods: a literature survey was performed from scientific papers describing real cases in which the dental method for human identification was performed and its applicability was analyzed, to verify its advantages, limitations, and efficiency. Results: it was found that Dentistry has a significant contribution to the identification of victims in events of multiple fatalities. The dental method was often the only possible method of human identification in cases with either too many fatal victims or situations where the bodies were too compromised for analysis. Final considerations: Forensic Dentistry plays an important role in the process of human identification of victims of mass disasters because teeth have features that allow the identification process of an individual, and sometimes it is the only material capable of analysis.

Keywords: Mass disasters. Human identification. Forensic dentistry. 


\section{Referências}

1. Brasil. Conselho Federal de Odontologia. Resolução CFO 63/2005: Consolidação das Normas para Procedimentos nos Conselhos de Odontologia. 2005. Disponível em URL: http:// www.cfo.org.br/download/pdf/consolidacao.pdf.

2. Berketa JW, James H, Lake AW. Forensic odontology involvement in disaster victim identification. Forensic Sci Med Pathol 2012; 8(2):148-56.

3. Brannon RB, Morlan WM. The USS lowa disaster: success of the forensic dental team. J Forensic Sci 2004; 49(5):1067-8.

4. Guay AH. The role dentists can play in mass casualty an disaster events. Dent Clin North Am 2007; 51(4):767-78.

5. Hinchliffe J. Forensic odontology: part 2. Major disasters. British Dental J 2010; 210(6):269-74

6. Ratnakar P, Singaraju GS. Methods of identification in forensic dentistry. An Essenc Dent 2010; 2(1):26-8.

7. Stavrianos C, Kokkas A, Eliades A. Applications of forensic dentistry: part i. Res J Med Sciences 2006; 4(3):179-86.

8. Stavrianos C, Dietrich EM, Stavrianos I, Petalotis N. The role of dentistry in the management of mass disasters and bioterrorism. Acta Stomatol Croat 2010; 44(2):110-9.

9. Valenzuela A, Martin de las Heras S, Marques T, Exposito N, Bohoyo JM. The application of dental methods of identification to human burn victims in a mass disaster. Int J Legal Med 2000; 113(4):236-9.

10. Zohn HK, Dashkow S, Aschheim KW, Dobrin LA, Glazer HS, Kirschbaum M, et al. The Odontology victim identification skill assessment system. J Forensic Sci 2010; 55(3):788-91.

11. Lake AW, James H, Berketa JW. Disaster victim identificatin: quality management from an odontology perpective. Forensic Sci Med Pathol 2012; 8(2):157-63.

12. Dumancic J, Kaic Z, Njemirovskij V, Brkic H, Zecevic D. Dental identification after two mass disasters in Croatia. Croot Med J 2001; 42(6):657-62

13. Valenzuela A, Marques T, Exposito N, Heras ML, García G. Comparative study of efficiency of dental methods for identification of burn victims in two bus accidents in Spain. Am $\mathrm{J}$ of Forensic Med and Pathol 2002; 23(4):390-3.

14. Brannon RB, Morlang WM. Jonestown tragedy revisited: the role of Dentistry. J Forensic Sci 2002; 47(1):3-7.

15. Compobasso CP, Flamingo R, Vinci F. Investigation on Italy's deadliest building collapse: forensic aspects of a mass disaster. J Forensic Sci 2003; 48(3):635:9.

16. Poisson P, Chapenoire S, Schuliar Y, Lamant M, Corvisier JM. Four major disasters in Aquitaine, France. Use of odontologic techniques for identification. Am J Forensic Med and Pathol 2003; 24(2):160-3.

17. Valck E. Major incident response: collecting ante-mortem data. For Sci Int 2006; 159(1):15-9.

18. Naiman M, Larsen AK, Valentin PR. The role of the dentist at crime scenes. Dent Clin North Am 2007; 51(4):837-56.

19. Nuzzolese E, Di Vella G. Future project concernung mass disaster management: a forensic Odontology prospectus. Int Dent J 2007; 57(4):261-6.
20. Sweet D. Forensic dental identification. Forense Sci Int 2010; 201(1):3-4.

21. Melo SL, Santos TS, Nascimento EDO, Marzola C, Silva EDO, Gerbi M. A importância da Odontologia Forense em acidentes em massa [periódico online] 2010. Disponível em URL: http://www.actiradentes.com.br/revista/2010/ textos/13RevistaATO-Desastres_em_massa-2010.pdf.

22. Leite MM, Amorim ACO, Gomes TD, Prado MN, Silva RF. Importância da atuação do odontolegista no processo de identificação humana de vítimas de desastre aéreo. Rev Odontol Bras Central 2011; 20(52):52-8.

23. Shekar Chandra BR, Reddy CVK. Role of dentist in person identification. Indian J Dent Res 2009; 20(3):356-60.

24. Blau S, Briggs CA. The role of forensic anthropology in disaster victim Identification (DVI). Forense Sci Int 2010; 205(2011):29-35.

25. The forensic odontologist: roles and responsibilities. Dental Nursing 2010; 6(12):710-3.

26. International Criminal Police Organization. Interpol DVI Guide. Lyon: OIPC - Interpol; 2009. Disponível em URL: http://www.interpol.int/INTERPOL-expertise/Forensics/ DVI-Pages/DVI-guide.

27. American Board of Forensic Odontology. Diplomates Reference Manual 2011 [periódico online] 2011. Disponível em URL: http://www.abfo.org/pdfs/ABFO_Reference_Manual_ for_3-2011.pdf.

\section{Endereço para correspondência:}

Ricardo Henrique Alves da Silva Avenida do Café, s/n, Bairro Monte Alegre 14040-904 Ribeirão Preto, SP Fone: (16) 3602-3969; Fax: (16) 3602-4102 E-mail: ricardohenrique@usp.br

Recebido: 31 /07/2013. Aceito: 07/10/2013. 